\title{
The effect and optimal dose of sufentanil in reducing injection pain of microemulsion propofol
}

\author{
Dong Hun Chung, Nan Sook Kim, Mi Kyoung Lee, and Hee-kyung Jo \\ Department of Anesthesiology and Pain Medicine, Korea University Guro Hospital, Seoul, Korea
}

Background: Propofol is used as an induction and maintenance agent for general anesthesia but it can cause adverse reactions like hyperlipidemia, growth of microorganisms, and pulmonary embolisms. Microemulsion propofol was developed to avoid these side effects but incidence and severity of pain on injection is higher than with lipid emulsion propofol. We aimed to compare the effects of sufentanil in analgesic doses for reducing the injection pain of microemulsion propofol.

Methods: The candidates included eighty patients, 19-60 years old and ASA I-II. They were randomly classified into four groups and pretreated with normal saline, sufentanil $0.1 \mu \mathrm{g} / \mathrm{kg}, 0.2 \mu \mathrm{g} / \mathrm{kg}$ or $0.3 \mu \mathrm{g} / \mathrm{kg}$ before injection of microemulsion propofol. Five minutes after receiving pretreatment drug, $2 \mathrm{mg} / \mathrm{kg}$ of microemulsion propofol was injected and VAS was recorded.

Results: There were no significant differences in the incidence of injection pain among the groups. Severity of injection pain was significantly lower in the sufentanil $0.3 \mu \mathrm{g} / \mathrm{kg}$ group than normal saline and sufentanil $0.1 \mu \mathrm{g} /$ kg group. Significant differences in blood pressure and heart rate were observed in sufentanil groups only after endotracheal intubation. One patient each in sufentanil $0.1 \mu \mathrm{g} / \mathrm{kg}$ and $0.3 \mu \mathrm{g} / \mathrm{kg}$ group experienced mild cough, one from sufentanil $0.3 \mu \mathrm{g} / \mathrm{kg}$ group experienced dizziness and another showed signs of hypoxia. One patient each in normal saline and sufentanil $0.1 \mu \mathrm{g} / \mathrm{kg}$ group showed clinical symptoms of phlebitis in the injection area.

Conclusions: Pretreatment with sufentanil $0.3 \mu \mathrm{g} / \mathrm{kg}$ reduced the severity of microemulsion propofol injection pain without increasing arterial blood pressure and heart rate after endotracheal intubation. (Korean J Anesthesiol 2011; 60: 83-89)

Key Words: Injection pain, Microemulsion propofol, Sufentanil.

Received: July 21, 2010. Revised: September 1, 2010. Accepted: September 7, 2010.

Corresponding author: Nan Sook Kim, M.D., Ph.D., Department of Anesthesiology and Pain Medicine, Korea University Guro Hospital, 80, Guro-dong, Guro-gu, Seoul 152-703, Korea. Tel: 82-2-2626-1437, Fax: 82-2-851-9897, E-mail: nskim@korea.ac.kr

(c) This is an open-access article distributed under the terms of the Creative Commons Attribution Non-Commercial License (http:// creativecommons.org/licenses/by-nc/3.0/), which permits unrestricted non-commercial use, distribution, and reproduction in any medium, provided the original work is properly cited. 


\section{Introduction}

Propofol is absorbed rapidly in central nerve tissue, assists with fast establishment of anesthesia, redistributes and metabolizes promptly from the central tissue to other tissues, and has a short half-life. For these reasons, it is used to induce general anesthesia, but it might cause vascular pain in case of injection [1]. Frequently used lipid emulsion propofol has $1 \%$ propofol dissolved in $10 \%$ soy bean oil, including $2.25 \%$ glycerol and $1.2 \%$ purified egg phosphatide (lecithin, emulsifier). However, this may lead to pulmonary embolism [2,3], and soy bean oil might facilitate microorganism proliferation [4,5]. In addition, adverse effects caused by the injection of lipid profiles, such as hypercholesterol and pancreatitis are reported $[1,6]$.

Microemulsion propofol is developed to remove or reduce adverse effects such as hypercholesterol, microorganism proliferation, and pulmonary embolism by eliminating lipid profiles, and it is pharmacodynamically and biologically equal to ingredients of lipid emulsion propofol. There is no difference in effects or safety within dose ranges (2 $\mathrm{mg} / \mathrm{kg}$ ) [7-9], but it is shown that pain is more severe in the case of injection compared to lipid emulsion propofol [10].

As for lipid emulsion propofol, several methods are assessed in clinical trials to prevent or reduce injection pain. One method is the injection of small amounts of opioids before injecting lipid emulsion propofol $[11,12]$. However, a study reported that pain was not effectively reduced by injecting $0.01 \mathrm{mg}(0.15 \mu \mathrm{g} /$ $\mathrm{kg} / \mathrm{min}$ ) of $2 \mathrm{ml}$ sufentanil [12]. There is no study available on the effects of sufentanil on microemulsion propofol, which has more severe injection pain.

In this study, $0.1 \mu \mathrm{g} / \mathrm{kg}, 0.2 \mu \mathrm{g} / \mathrm{kg}$, and $0.3 \mu \mathrm{g} / \mathrm{kg}$ of sufentanil were injected as a pretreatment to reduce the injection pain of microemulsion propofol. The effects on injection pain, changes in blood pressure and heart rate after endotracheal intubation, and abnormal responses were compared. Based on these results, we attempted to determine the optimal dose of sufentanil for the reduction of injection pain.

\section{Materials and Methods}

This study included 80 patients who were scheduled for general anesthesia and aged between 19 and 60 years old. They were selected by random sampling and double blinding, which included in physical status classification I, II of American Society of Anesthesiologists. After obtaining approval of the institutional review board, sufficient explanation of the study purpose and methods was given to the patients and informed consent was obtained. Patients who had experience of hypersensitivity towards propofol, epileptics, patients with cardiovascular and respiratory system diseases, kidney, liver and hypovolemic patients, pregnant women, persons under 40 $\mathrm{kg}$ and over $90 \mathrm{~kg}$, and patients over Mallampati grade 3 were excluded from this study.

Before leaving the ward, midazolam $0.04 \mathrm{mg} / \mathrm{kg}$ and glycopyrrolate $0.2 \mathrm{mg}$ were injected as premedication. The patients took 20-gauge of intravenous line on the back of his hand, and maintained $5 \mathrm{ml} / \mathrm{kg} / \mathrm{hr}$ of fluid speed after checking whether there was any inconvenience or abnormal status even in case of fast fluid injection prior to the clinical trials. Before induction, hemodynamic responses of patients were monitored by installing ECG, pulse oxygen saturation $\left(\mathrm{SpO}_{2}\right)$, and noninvasive blood pressure.

General anesthesia was carried out by microemulsion propofol (Aquafol ${ }^{\circledR}$, Daewon Pharm., Korea), and patients were divided into 4 groups by a computer-generated random table, which included the saline pretreatment group (control group), sufentanil $0.1 \mu \mathrm{g} / \mathrm{kg}$ pretreatment group, sufentanil $0.2 \mu \mathrm{g} /$ $\mathrm{kg}$ pretreatment group, and sufentanil $0.3 \mu \mathrm{g} / \mathrm{kg}$ pretreatment group.

All patients were explained that injection pain might occur and as for pretreatment drugs, an anesthesiologist who did not participate in the experiment, combined the appropriate doses of saline $5 \mathrm{ml}$ or sufentanil for each group with saline before induction, made the total $5 \mathrm{ml}$, and kept it at room temperature. The anesthesiologist who participated in the experiment did not know the division between groups. After checking whether the breath of patients were well maintained by monitoring sufficient oxygen supply through masks, pulse oxygen saturation, and respiration rate via various monitoring equipments, pretreatment was carried out for 10 seconds [11]. Considering 5 minutes, which shows the maximized effect of sufentanil [12], if the respiration was not maintained, patients were asked to take deep breath orally. In case there was no response, a face mask was prepared for ventilation assistance.

According to each group, 5 minutes after saline or sufentanil pretreatment, $2 \mathrm{mg} / \mathrm{kg}$ microemulsion propofol (1\%) was injected at a speed of $1 \mathrm{ml} / \mathrm{sec}[11,13]$, and after loss of consciousness to enable muscle relaxation and endotracheal intubation, all patients were injected with succinylcholine 1 $\mathrm{mg} / \mathrm{kg}$, ventilated with $100 \%$ oxygen using a face mask, and endotracheal intubation was carried out. After endotracheal intubation, vecuronium $0.1 \mathrm{mg} / \mathrm{kg}$ was injected, and desflurane or sevoflurane was applied for anesthesia maintenance, whereas $\mathrm{EtCO}_{2}$ was maintained as $30-35 \mathrm{mmHg}$ with nitrous oxide $50 \%$ and oxygen as fresh gas flow $4 \mathrm{~L} / \mathrm{min}$.

Systolic and diastolic blood pressure and heart rate were measured before pretreatment (baseline), 5 minutes after sufentanil injection, after loss of eyelid reflex, right after endotracheal intubation, and 5 minutes after endotracheal intubation. 
As a measure of evaluation on pain, visual analogue scale score (VAS; $0 \mathrm{~mm}$, no pain, $100 \mathrm{~mm}$, worst pain imaginable) was explained to the patients before the surgery, and this study divided the level of pain in detail into none, mild pain over 10 $\mathrm{mm}$ and less than $30 \mathrm{~mm}$, moderate pain over $30 \mathrm{~mm}$ and less than $70 \mathrm{~mm}$, and severe pain over $70 \mathrm{~mm}$. Before eyelid reflex loss, if the patients claimed pain voluntarily, VAS score was assessed by questions, and if there was no voluntary pain claim, the answers were derived by questions orally at intervals of 5 seconds and the relevant anesthesiologist evaluated the degree of pain [12].

We observed whether skeletal muscle stiffness or hypoxia [11] occurred through the patients' response or pulse oxygen saturation until microemulsion propofol injection was done. We recorded bradycardia (under 45 beats/min in this study), hypoxia $\left(\mathrm{SpO}_{2}<90 \%\right)$, cough and chest wall tightness or dizziness by a medical examination after sufentanil injection was done. Erythema, muscle spasm, phlebitis due to microemulsion propofol injection, and abnormal responses (pain, edema, phlebitis) of the injection area were observed in a recovery room and 24 hours after the surgery. An anesthesiologist evaluated recall on injection pain in a recovery room without knowing the group classification.

Effect size of 4-group based on the results of the pilot test was 0.379 , and the total sample size was 80 including 20 in each group, calculated by one-way ANOVA, two-sided test, level of significance 0.05 , and power 0.8 .

All results were shown as mean \pm standard deviation, and the SPSS program (version 12.0, SPSS Inc., USA) was used for statistical analysis. Analysis of variance (ANOVA) was applied to age, weight, height, and chi-square test for gender to analyze demographic data. Chi-square test was applied to compare the effects of sufentanil pretreatment to the incidence and the degree of injection pain of microemulsion propofol. For comparison on doses, ANOVA and post hoc test (Duncan) were applied. For blood pressure and heart rate measurements, one way repeated ANOVA was applied to compare the difference in groups and the Tukey test was applied for post-hoc analysis and one way ANOVA was applied to compare the difference

Table 1. Demographic Characteristics of Patients

\begin{tabular}{lcccc}
\hline & Normal & \multicolumn{3}{c}{ Sufentanil } \\
\cline { 3 - 5 } \multicolumn{1}{c}{ Groups } & $\begin{array}{c}\text { saline } \\
(\mathrm{n}=20)\end{array}$ & $\begin{array}{c}0.1 \mu \mathrm{g} / \mathrm{kg} \\
(\mathrm{n}=20)\end{array}$ & $\begin{array}{c}0.2 \mu \mathrm{g} / \mathrm{kg} \\
(\mathrm{n}=20)\end{array}$ & $\begin{array}{c}0.3 \mu \mathrm{g} / \mathrm{kg} \\
(\mathrm{n}=20)\end{array}$ \\
\hline Age (yr) & $37.7 \pm 11.1$ & $42.8 \pm 11.3$ & $41.4 \pm 11.6$ & $39.3 \pm 1.8$ \\
Weight $(\mathrm{kg})$ & $62.0 \pm 5.9$ & $62.5 \pm 8.8$ & $67.3 \pm 12.0$ & $63.9 \pm 9.1$ \\
Height $(\mathrm{cm})$ & $158.9 \pm 7.2$ & $162.1 \pm 6.9$ & $165.0 \pm 9.5$ & $161.9 \pm 9.3$ \\
Gender (M/F) & $3 / 17$ & $7 / 13$ & $11 / 9$ & $6 / 14$ \\
\hline
\end{tabular}

Values are mean \pm SD or number of patients. No significant differences between groups. between groups and the Holm-Sidak test was applied for posthoc analysis. It was assumed that $\mathrm{P}$ value $<0.05$ was statistically significant.

\section{Results}

The age, weight and height of each group did not show any significant difference. Overall, females $(66.3 \%)$ were higher than their male counterparts (34\%), but there was no significant difference by each group based on gender $(\mathrm{P}>0.05$, Table 1$)$.

Regarding the degree of pain, VAS was $70.5 \pm 12.3 \mathrm{~mm}$ in the control group, and $48 \pm 14.7 \mathrm{~mm}, 41.5 \pm 24.5 \mathrm{~mm}$, and 33 $\pm 21.3 \mathrm{~mm}$ in sufentanil $0.1 \mu \mathrm{g} / \mathrm{kg}, 0.2 \mu \mathrm{g} / \mathrm{kg}$, and $0.3 \mu \mathrm{g} / \mathrm{kg}$ pretreatment group, respectively. VAS was significantly lower in sufentanil pretreatment groups than in the control group. The degree of pain was significantly lower in sufentanil 0.3 $\mu \mathrm{g} / \mathrm{kg}$ pretreatment group compared to sufentanil $0.1 \mu \mathrm{g} / \mathrm{kg}$ pretreatment group $(\mathrm{P}=0.000$, Table 2$)$. With regards to the incidence of injection pain, there were 20 persons in the control group, 20 persons in the sufentanil $0.1 \mu \mathrm{g} / \mathrm{kg}$ pretreatment group, 19 persons in the sufentanil $0.2 \mu \mathrm{g} / \mathrm{kg}$ pretreatment group, and 18 persons in the sufentanil $0.3 \mu \mathrm{g} / \mathrm{kg}$ pretreatment group, which did not show a significant difference between the control and sulfentanil pretreatment groups. As for mild pain, 8 persons in the sufentanil $0.2 \mu \mathrm{g} / \mathrm{kg}$ pretreatment group and 11 in the sufentanil $0.3 \mu \mathrm{g} / \mathrm{kg}$ pretreatment group were significantly higher than 0 in the control group and 4 in the sufentanil $0.1 \mu \mathrm{g} / \mathrm{kg}$ pretreatment group. As for moderate pain, 13 persons in the sufentanil $0.1 \mu \mathrm{g} / \mathrm{kg}$ pretreatment group was significantly higher than 7 persons in the sufentanil $0.2 \mu \mathrm{g} / \mathrm{kg}$ pretreatment group and 5 persons in $0.3 \mu \mathrm{g} / \mathrm{kg}$ pretreatment group. As for severe pain, sufentanil pretreatment groups were significantly lower than the control group $(P=0.000$, Table 3$)$. As for over moderate pain, all patients in control group, 16 persons in sufentanil $0.1 \mu \mathrm{g} / \mathrm{kg}$ pretreatment group, 11 persons in sufentanil $0.2 \mu \mathrm{g} / \mathrm{kg}$ pretreatment group, 7 persons in sufentanil $0.3 \mu \mathrm{g} / \mathrm{kg}$ pretreatment group claimed pain, which does not show significant difference between the control and sufentanil pretreatment groups.

Table 2. Comparison of Visual Analogue Scale (VAS) Score between Groups

\begin{tabular}{|c|c|c|c|c|}
\hline \multirow[b]{2}{*}{ Groups } & \multirow{2}{*}{$\begin{array}{l}\text { Normal } \\
\text { saline } \\
(n=20)\end{array}$} & \multicolumn{3}{|c|}{ Sufentanil } \\
\hline & & $\begin{array}{c}0.1 \mu \mathrm{g} / \mathrm{kg} \\
(\mathrm{n}=20)\end{array}$ & $\begin{array}{c}0.2 \mu \mathrm{g} / \mathrm{kg} \\
(\mathrm{n}=20)\end{array}$ & $\begin{array}{c}0.3 \mu \mathrm{g} / \mathrm{kg} \\
(\mathrm{n}=20)\end{array}$ \\
\hline $\begin{array}{l}\text { VAS score } \\
(\mathrm{mm})\end{array}$ & $70.5 \pm 12.3$ & $48.0 \pm 14.7^{*}$ & $41.5 \pm 24.5^{*}$ & $33.0 \pm 21.3^{*, \dagger}$ \\
\hline
\end{tabular}

$\overline{\text { Values are mean } \pm \mathrm{SD} .{ }^{*} \mathrm{P}<0.05 \text { vs. normal saline group, }{ }^{\dagger} \mathrm{P}<0.05}$ vs. sufentanil $0.1 \mu \mathrm{g} / \mathrm{kg}$. 
Table 3. Incidence and Intensity of Pain during Injection of Microemulsion Propofol and Recalls in Post Anesthesia Care Unit (PACU)

\begin{tabular}{lcccc}
\hline & Normal & \multicolumn{3}{c}{ Sufentanil } \\
\cline { 3 - 5 } & $\begin{array}{c}\text { saline } \\
(\mathrm{n}=20)\end{array}$ & $\begin{array}{c}0.1 \mu \mathrm{g} / \mathrm{kg} \\
(\mathrm{n}=20)\end{array}$ & $\begin{array}{c}0.2 \mu \mathrm{g} / \mathrm{kg} \\
(\mathrm{n}=20)\end{array}$ & $\begin{array}{c}0.3 \mu \mathrm{g} / \mathrm{kg} \\
(\mathrm{n}=20)\end{array}$ \\
\hline Pain & & & & \\
$\quad$ None & $0(0)$ & $0(0)$ & $1(5)$ & $2(10)$ \\
$\quad$ Mild & $0(0)$ & $4(20)$ & $8(40)^{*, \dagger}$ & $11(55)^{*, \dagger}$ \\
Moderate & $4(20)$ & $13(65)$ & $7(35)^{\dagger}$ & $5(25)^{\dagger}$ \\
$\quad$ Severe & $16(80)$ & $3(15)^{*}$ & $4(20)^{*}$ & $2(10)^{*}$ \\
Total incidence & $20(100)$ & $20(100)$ & $19(95)$ & $18(90)$ \\
Recall & $14(70)$ & $13(65)$ & $12(63.2)$ & $4(22.2)^{*}$
\end{tabular}

Values are numbers of patient (\%). Mild pain: visual analog scale $<$ $30 \mathrm{~mm}$, Moderate pain: visual analog scale $30-70 \mathrm{~mm}$, Severe pain: visual analog scale $>70 \mathrm{~mm}$. ${ }^{*} \mathrm{P}<0.05$ vs. normal saline group, ${ }^{\dagger} \mathrm{P}<$ 0.05 vs. sufentanil $0.1 \mu \mathrm{g} / \mathrm{kg}$.

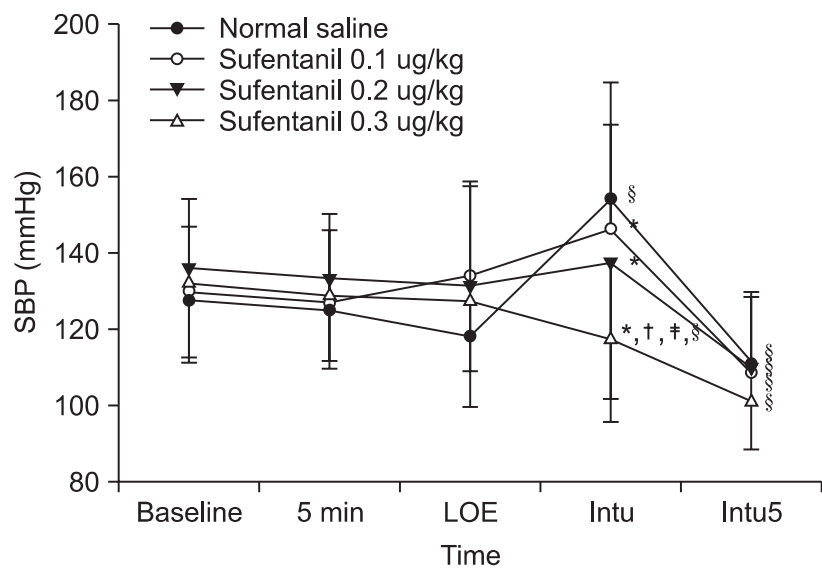

Fig. 1. Change of systolic blood pressure (SBP) from pre-anesthesia to different times for endotracheal intubation. Values are mean \pm SD. SBP: systolic blood pressure, 5 min: 5 minutes after pretreatment, LOE: loss of eyelid reflex, Intu: after tracheal intubation, Intu5: 5 minutes after tracheal intubation. ${ }^{*} \mathrm{P}<0.05$ vs. normal saline group, ${ }^{\dagger} \mathrm{P}<0.05$ vs. sufentanil $0.1 \mu \mathrm{g} / \mathrm{kg},{ }^{\dagger} \mathrm{P}<0.05$ vs. sufentanil $0.2 \mu \mathrm{g} / \mathrm{kg}$, ${ }^{\S} \mathrm{P}<0.05$ vs. baseline value.

Systolic and diastolic blood pressure significantly increased from the baseline in the control group right after endotracheal intubation and significantly decreased 5 minutes after endotracheal intubation. Systolic and diastolic blood pressure decreased significantly in the sufentanil $0.1 \mu \mathrm{g} / \mathrm{kg}$ and $0.2 \mu \mathrm{g} /$ $\mathrm{kg}$ pretreatment groups 5 minutes after endotracheal intubation and decreased significantly in the sufentanil $0.3 \mu \mathrm{g} / \mathrm{kg}$ pretreatment groupright after endotracheal intubation and 5 minutes after endotracheal intubation. Systolic and diastolic blood pressure decreased significantly in the sufentanil 0.3 $\mu \mathrm{g} / \mathrm{kg}$ pretreatment group right after endotracheal intubation compared to the control, sufentanil $0.1 \mu \mathrm{g} / \mathrm{kg}$ and sufentanil 0.2 $\mu \mathrm{g} / \mathrm{kg}$ pretreatment groups (Fig. 1 and 2). Heart rate significantly increased from the baseline in the control group right after

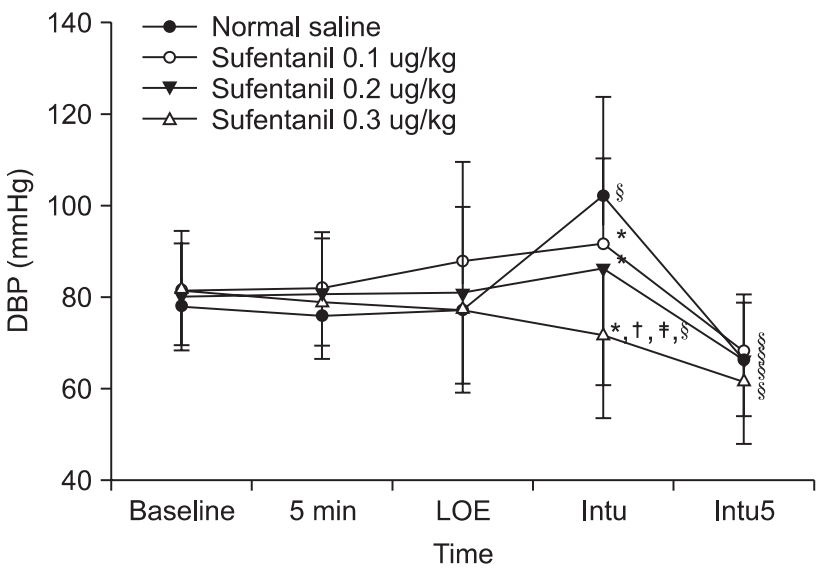

Fig. 2. Change of diastolic blood pressure (DBP) from pre-anesthesia to different times for endotracheal intubation. Values are mean \pm SD DBP: diastolic blood pressure, $5 \mathrm{~min}$ : 5 minutes after pretreatment, LOE: loss of eyelid reflex, Intu: after tracheal intubation, Intu5: 5 minutes after tracheal intubation. ${ }^{*} \mathrm{P}<0.05$ vs. normal saline group, ${ }^{\dagger} \mathrm{P}<0.05$ vs. sufentanil $0.1 \mu \mathrm{g} / \mathrm{kg},{ }^{\ddagger} \mathrm{P}<0.05$ vs. sufentanil $0.2 \mu \mathrm{g} / \mathrm{kg}$, ${ }^{\S} \mathrm{P}<0.05$ vs. baseline value.

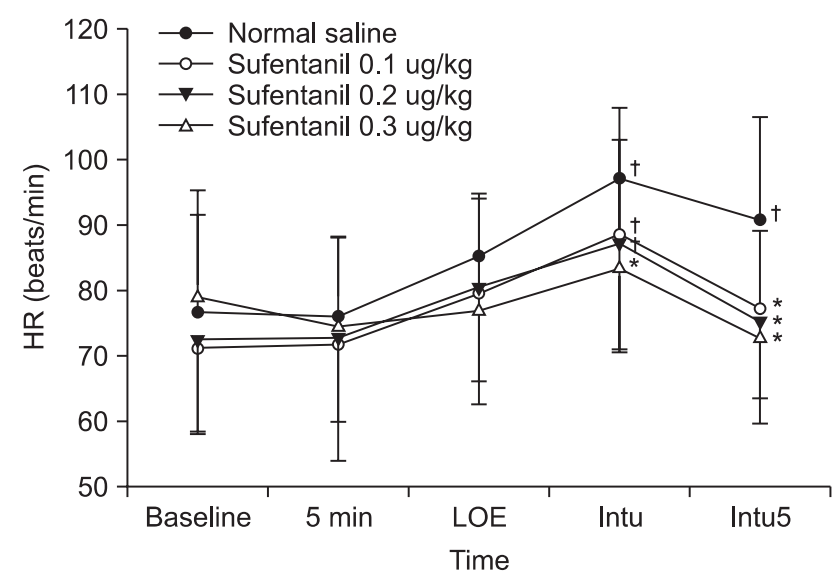

Fig. 3. Change of heart rate (HR) from pre-anesthesia to different times for endotracheal intubation. Values are mean \pm SD. HR: heart rate, 5 min: 5 minutes after pretreatment, LOE: loss of eyelid reflex, Intu: after tracheal intubation, Intu5: 5 minutes after tracheal intubation. ${ }^{*} \mathrm{P}<0.05$ vs. normal saline group, ${ }^{\dagger} \mathrm{P}<0.05$ vs. baseline value.

endotracheal intubation and 5 minutes after endotracheal intubation, and significantly increased in sufentanil $0.1 \mu \mathrm{g} /$ $\mathrm{kg}$ and sufentanil $0.2 \mu \mathrm{g} / \mathrm{kg}$ pretreatment groups right after endotracheal intubation. Right after endotracheal intubation, the heart rate significantly decreased in the sufentanil $0.3 \mu \mathrm{g} /$ $\mathrm{kg}$ pretreatment group compared to the control group. Five minutes after endotracheal intubation, sufentanil $0.1 \mu \mathrm{g} / \mathrm{kg}, 0.2$ $\mu \mathrm{g} / \mathrm{kg}, 0.3 \mu \mathrm{g} / \mathrm{kg}$ pretreatment groups significantly decreased compared to the control group (Fig. 3).

After pretreatment injection, 1 person complained of mild cough in both the sufentanil $0.1 \mu \mathrm{g} / \mathrm{kg}$ and $0.3 \mu \mathrm{g} / \mathrm{kg}$ 
pretreatment group. One person claimed slight dizziness in the sufentanil $0.3 \mu \mathrm{g} / \mathrm{kg}$ pretreatment group, and 1 person in the sufentanil $0.3 \mu \mathrm{g} / \mathrm{kg}$ pretreatment group had their pulse oxygen saturation drop temporarily to $86 \%$ after injection, but recovered to $100 \%$ after taking a deep breath.

One patient each with symptoms of phlebitis on the injection area 24 hours after surgery was observed in the control and sufentanil $0.1 \mu \mathrm{g} / \mathrm{kg}$ pretreatment group, respectively.

43 patients recalled injection pain in the recovery room; 14 in the control group, 13 in the sufentanil $0.1 \mu \mathrm{g} / \mathrm{kg}$ pretreatment group, 12 in the sufentanil $0.2 \mu \mathrm{g} / \mathrm{kg}$ pretreatment group, and 4 in the sufentanil $0.3 \mu \mathrm{g} / \mathrm{kg}$ pretreatment group. In addition, injection pain was recalled less in the sufentanil $0.3 \mu \mathrm{g} / \mathrm{kg}$ pretreatment group compared to the control group (Table 3).

\section{Discussion}

Injecting microemulsion propofol after pretreatment of sufentanil did not reduce the incidence of injection pain significantly compared to cases where pretreatment was not carried out. In pretreatment with sufentanil $0.3 \mu \mathrm{g} / \mathrm{kg}$, the degree of injection pain reduced significantly.

As for microemulsion propofol $\left(\right.$ Aquafol $^{\circledR}$ ), oil phase is $1 \%$ propofol itself, and aqueous phase is distilled water and phosphate buffer solution. As surfactants (emulsifier), there is $10 \%$ purified poloxamer 188 (PP188), a nonionic block copolymer surfactant, and for nonionic surfactant, macrogol-15-hydroxysterate (0.7\% polyethylene glycol 660 hydroxystearate, Solutol HS 15; BASF Company Ltd., Seoul, Korea) was freshly added for recomposing microemulsion propofol [7], and the size of droplet organizing emulsion was 0.1 $\mu \mathrm{m}$ or less than $100 \mathrm{~nm}$ [4].

Injection pain of lipid emulsion propofol occurred in 28$90 \%$ of subjects [1]. According to the study of Sim et al. [10], when assessing injection pain as VAS $(0-100 \mathrm{~mm})$ in case of anesthesia induction, VAS of microemulsion propofol was 59 $\mathrm{mm}$, which is significantly higher than $24 \mathrm{~mm}$ of lipid emulsion propofol, and incidence of injection pain over VAS $30 \mathrm{~mm}$ was $69.7 \%$ for microemulsion propofol and $42.3 \%$ for lipid emulsion propofol. It is known that aqueous free propofol causes pain, depending on concentration [14]. As for aqueous free propofol concentration, microemulsion propofol (Aquafol ${ }^{\circledR}$ ) is $63.3 \pm$ $1.2 \mu \mathrm{g} / \mathrm{ml}$ and lipid emulsion propofol (Diprivan ${ }^{\circledR}$ ) is $12.4 \pm 0.7$ $\mu \mathrm{g} / \mathrm{ml}$, which is about 5 -fold higher and pain is caused more in microemulsion propofol [15].

There are several methods to reduce injection pain of propofol, including diluting propofol with $5 \%$ glucose solution or $10 \%$ intralipid [1], using opioids (fentanyl, remifentanil, etc.) as pretreatment $[11,12]$, injecting lidocaine through tourniquet before propofol injection [13], injecting cold $\left(4^{\circ} \mathrm{C}\right)$ saline before propofol injection [16], mixing propofol with lidocaine [1], and using the large vein [12].

In this study, pretreatment with sufentanil, an opioid, which is one of the methods to prevent injection pain of microemulsion propofol, was carried out. Among sufentanil pretreatment groups, the degree of pain was significantly low, compared to the control group, but there was no significant difference in the incidence of injection pain. According to Honarmand and Safavi [12], in the case of injecting lipid emulsion propofol, pretreatment with sufentanil $0.01 \mathrm{mg}$ did not reduce the incidence and degree of injection pain, because the injected dose level of sufentanil was not sufficient or injection time period of lipid emulsion propofol after pretreatment was 1 minute, which was not adequate. In this study, the reason why the incidence of injection pain of microemulsion propofol did not reduce may have been the injected dose level of sufentanil was not sufficient $(0.1 \mu \mathrm{g} / \mathrm{kg}$ or $0.2 \mu \mathrm{g} / \mathrm{kg})$. Even after increasing the dose to $0.3 \mu \mathrm{g} / \mathrm{kg}$, the incidence did not reduce but it was shown that the degree of injection pain reduced significantly. Since microemulsion propofol has more injection pain than lipid emulsion propofol, it is expected that by applying a dose higher than $0.3 \mu \mathrm{g} / \mathrm{kg}$ of sufentanil, there may be reduction of the incidence or degree of injection pain in the additional study.

According to Song et al. [17], as a result of comparison between injection pain of lipid emulsion propofol and lower lipid propofol, the incidence of mild injection pain was $39 \%$ after injecting $1 \%$ lidocaine $0.5 \mathrm{mg} / \mathrm{kg}$ to reduce injection pain, sufentanil $0.1 \mu \mathrm{g} / \mathrm{kg}$ or fentanyl $1 \mu \mathrm{g} / \mathrm{kg}$ for anesthetic induction, and injecting lower lipid propofol. In our study, all patients in the sufentanil $0.1 \mu \mathrm{g} / \mathrm{kg}$ pretreatment group claimed over mild pain. This means that Song's study carried out pretreatment with lidocaine, injected lower lipid propofol, and did not analyze sufentanil and fentanyl separately, which causes the difference to the results of our study. Sufentanil reduces injection pain of microemulsion propofol, but injection pain is not removed completely within the used analgesic dose (0.1$0.3 \mu \mathrm{g} / \mathrm{kg})$.

Sufentanil is a synthetic opioid, which is phenylpiperidinetype, and mostly acts in the central nervous system, but can also act as an analgesic through opioid receptors of peripheral sensory nerves due to the peripheral mechanism [18]. Sufentanil shows a rapid onset of action, reaches the maximized effects at about 5-7 minutes [19], prevents hypertension and tachycardia during surgery [20], and does not accumulate in tissues. Therefore, if applying the same amount, compared to fentanyl which is a similar type of opioid, it is possible to recover faster from surgery [21]. However, by applying a high dose of sufentanil (over $2.6 \mu \mathrm{g} / \mathrm{kg}$ ), respiratory depression, increase in airway resistance, or muscle stiffness after surgery may occur, which is less harmful than the effects of fentanyl 
[20]. This is related to the dose of sufentanil, and in this study, a dose of up to $0.1-0.3 \mu \mathrm{g} / \mathrm{kg}$ was injected as the analgesic dose $[12,21]$. Other adverse effects include drowsiness, sedation, clouding of consciousness, postoperative nausea, vomiting, and constipation. The incidence of respiratory depression, which is the most severe adverse effect, occurred about $0.1-1 \%$ of the time, regardless of injection routes, but was still possible to prevent [21]. In this study, one patient in the sufentanil 0.3 $\mu \mathrm{g} / \mathrm{kg}$ pretreatment group complained of dizziness, and pulse oxygen saturation of one patient dropped temporarily, which suggests that sufentanil might show central nervous system complications under $0.3 \mu \mathrm{g} / \mathrm{kg}$ dose, which is not a high dose based on the patients.

According to Böhrer et al. [22], when injecting $7 \mu \mathrm{g} / \mathrm{kg}$ fentanyl to the central veins, $45.9 \%$ of patients claimed coughing. It is assumed that this triggered chemoreflex of the lung, and in case of injecting to peripheral veins, one patient claimed coughing. In this study, it was shown that one person each in the sufentanil $0.1 \mu \mathrm{g} / \mathrm{kg}$ and sufentanil $0.3 \mu \mathrm{g} / \mathrm{kg}$ pretreatment groups claimed coughing, which means coughing may also be caused by a small amount.

Opioids suppress the reflex of upper respiratory tracts, trachea, lower respiratory system and obtund the reflex of somatic or autonomic nervous system in the case of endotracheal intubation [21]. In this study, there were no significant difference in baseline, 5 minutes after pretreatment, after loss of eyelid reflex, and 5 minutes after endotracheal intubation in systolic and diastolic blood pressure for each group but right after endotracheal intubation, systolic and diastolic blood pressure reduced significantly in sufentanil pretreatment groups compared to the control group. Heart rate significantly reduced in the sufentanil $0.3 \mu \mathrm{g} / \mathrm{kg}$ pretreatment group right after endotracheal intubation. This means that stable blood pressure and heart rate are maintained in pretreatment of sufentanil $0.3 \mu \mathrm{g} / \mathrm{kg}$.

After injecting lipid emulsion propofol (Diprivan ${ }^{\circledR}$ ), the incidence of phlebitis is reported as below 6.6\% [23], and in this study, one person each was observed in the control and sufentanil $0.1 \mu \mathrm{g} / \mathrm{kg}$ pretreatment group, for whom the incidence of phlebitis was $2.5 \% 24$ hours after the surgery. Both suffered from severe injection pain, and as a result of observing the vein after replacing injection area, they improved without aggravation. However, this phlebitis might have occurred without injection pain [23], so it is important to carefully monitor the injection area after the injection.

According to Nathanson et al. [24], as for patients with premedication of benzodiazepine, $52 \%$ recalled injection pain of lipid emulsion propofol. In our study, 53\% of patients also recalled injection pain, which was significantly low in the sufentanil $0.3 \mu \mathrm{g} / \mathrm{kg}$ pretreatment group (22.2\%). It is thought that the incidence of over moderate pain was lower in the sufentanil $0.3 \mu \mathrm{g} / \mathrm{kg}$ pretreatment group compare to the other groups.

In summary, with pretreatment using sufentanil, the degree of injection pain of microemulsion propofol decreased, and in the case of injecting $0.3 \mu \mathrm{g} / \mathrm{kg}$ of sufentanil, the degree of injection pain reduced, with minimal changes in blood pressure and heart rate on stimulation of endotracheal intubation without significant adverse effects.

\section{References}

1. Smith I, White PF, Nathanson M, Gouldson R. Propofol. An update on its clinical use. Anesthesiology 1994; 81: 1005-43.

2. Han J, Davis SS, Washington C. Physical properties and stability of two emulsion formulations of propofol. Int J Pharm 2001; 215: 20720.

3. Park JW, Park ES, Chi SC, Kil HY, Lee KH. The effect of lidocaine on the globule size distribution of propofol emulsions. Anesth Analg 2003; 97: 769-71.

4. Baker MT, Naguib M. Propofol: the challenges of formulation. Anesthesiology 2005; 103: 860-76.

5. Klein J, Huisman I, Menon AG, Leenders CM, van Eeghem KH, Vos MG, et al. Postoperative infection due to contaminated propofol. Ned Tijdschr Geneeskd 2010; 154: A767.

6. Devlin JW, Lau AK, Tanios MA. Propofol-associated hypertriglyceridemia and pancreatitis in the intensive care unit: an analysis of frequency and risk factors. Pharmacotherapy 2005; 25: 1348-52.

7. Lee SH, Ghim JL, Song MH, Choi HG, Choi BM, Lee HM, et al. Pharmacokinetics and pharmacodynamics of a new reformulated microemulsion and the long-chain triglyceride emulsion of propofol in beagle dogs. Br J Pharmacol 2009; 158: 1982-95.

8. Kim KM, Choi BM, Park SW, Lee SH, Christensen LV, Zhou J, et al. Pharmacokinetics and pharmacodynamics of propofol microemulsion and lipid emulsion after an intravenous bolus and variable rate infusion. Anesthesiology 2007; 106: 924-34.

9. Morey TE, Modell JH, Shekhawat D, Shah DO, Klatt B, Thomas GP, et al. Anesthetic properties of a propofol microemulsion in dogs. Anesth Analg 2006; 103: 882-7.

10. Sim JY, Lee SH, Park DY, Jung JA, Ki KH, Lee DH, et al. Pain on injection with microemulsion propofol. Br J Clin Pharmacol 2009; 67:316-25.

11. Fujii Y, Itakura M. A comparison of pretreatment with fentanyl and lidocaine preceded by venous occlusion for reducing pain on injection of propofol: a prospective, randomized, double-blind, placebo-controlled study in adult Japanese surgical patients. Clin Ther 2009; 31: 2107-12.

12. Honarmand A, Safavi M. Prevention of propofol-induced injection pain by sufentanil: a placebo-controlled comparison with remifentanil. Clin Drug Investig 2008; 28: 27-35.

13. Picard $P$, Tramèr MR. Prevention of pain on injection with propofol: a quantitative systematic review. Anesth Analg 2000; 90: 963-9.

14. Doenicke AW, Roizen MF, Rau J, Kellermann W, Babl J. Reducing pain during propofol injection: the role of the solvent. Anesth Analg 1996; 82: 472-4. 
15. Lee EH, Lee SH, Park DY, Ki KH, Lee EK, Lee DH, et al. Physicochemical properties, pharmacokinetics, and pharmacodynamics of a reformulated microemulsion propofol in rats. Anesthesiology 2008; 109: 436-47.

16. Barker P, Langton JA, Murphy P, Rowbotham DJ. Effect of prior administration of cold saline on pain during propofol injection. A comparison with cold propofol and propofol with lignocaine. Anaesthesia 1991; 46: 1069-70.

17. Song D, Hamza M, White PF, Klein K, Recart A, Khodaparast O. The pharmacodynamic effects of a lower-lipid emulsion of propofol: a comparison with the standard propofol emulsion. Anesth Analg 2004; 98: 687-91.

18. Stein C. The control of pain in peripheral tissue by opioids. N Engl J Med 1995; 332: 1685-90.

19. Soulard A, Babre F, Bordes M, Meymat Y, Sztark F, Cros AM. Optimal dose of sufentanil in children for intubation after sevoflurane induction without neuromuscular block. Br J Anaesth 2009; 102: 680-5.

20. Chang J, Fish KJ. Acute respiratory arrest and rigidity after anesthesia with sufentanil: a case report. Anesthesiology 1985; 63: 710-1.

21. Miller R, Fleisher LA, Eriksson LI. Miller's anesthesia. 7th ed. Philadelphia, Churchill-Livingstone Elsevier. 2010, pp 769-814.

22. Böhrer H, Fleischer F, Werning P. Tussive effect of a fentanyl bolus administered through a central venous catheter. Anaesthesia 1990; 45: 18-21.

23. Kinoshita H, Kakutani T, Minonishi T, Mizumoto K, Hatano Y. Transient phlebitis induced by a bolus injection of propofol. J Anesth 2006; 20: 74-5.

24. Nathanson MH, Gajraj NM, Russell JA. Prevention of pain on injection of propofol: a comparison of lidocaine with alfentanil. Anesth Analg 1996; 82: 469-71. 